\title{
Beech Wood Impregnation with Hydrolyzed Wattle Tannin
}

\author{
Anna Oberle, ${ }^{\mathrm{a}, *}$ Zuzana Paschová, ${ }^{\mathrm{a}}$ Miklós Bak, ${ }^{\mathrm{b}}$ and Vladimír Gryc ${ }^{\mathrm{a}}$ \\ Tannins and their toxic effects against various decay organisms have been \\ interrelated for centuries. As natural products have gained more interest, \\ waste from several production fields abundant in tannins has yielded \\ promising components for wood preservation. In this work, the main \\ approach was to split condensed tannins into smaller fractions by chemical \\ hydrolysis and evaluate their suitability for beech wood impregnation. \\ Commercial extract from black wattle was treated with mineral acid of low \\ concentration. The volatile hydrochloric acid was completely removed \\ after reaction by evaporation in the course of freeze-drying. The modified \\ extract was then applied as aqueous solution into beech wood. The water \\ resistance of the modified beech wood was not increased significantly, and \\ scanning electron microscopy (SEM) showed no evidence of tannin \\ successful bonding within wood cells. Nevertheless, after strong leaching \\ cycles, part of the extract accumulated in fibers. Moreover, lyophilization \\ was found to be a suitable technique to eliminate volatile acids from \\ temperature-sensitive extracts, such as tannins. These findings could help \\ in the development of water-borne tannin formulations for wood protection, \\ while using phlobaphene formation as a potential natural pathway of \\ tannin autocondensation.
}

Keywords: Acacia mearnsii; Acid hydrolysis; Lyophilization; Fagus sylvatica; Wood modification; Leaching; SEM

Contact information: a: Department of Wood Science and Technology, Mendel University in Brno, Zemédělská 3, 61300 Brno, Czech Republic; b: Institute of Wood Sciences, University of Sopron, BajcsyZsilinszky utca 4, H-9400 Sopron, Hungary; *Corresponding author: anna.oberle@mendelu.cz.

\section{INTRODUCTION}

Wooden products have only limited lifetime and when exposed to humid conditions they undergo deterioration (Reinprecht 2016). Nowadays, the conventional water-borne wood preservation policy is slowly turning away from hazardous chromated copper arsenate/borate (CCA and CCB, respectively) to the development of i) self-healing surface coatings with fungicidal nanoparticles (e.g. silver Ag, zinc oxide $\mathrm{ZnO}$, titanium dioxide $\mathrm{TiO}_{2}$, etc.) (Borges et al. 2018; Teng et al. 2018); and to the ii) fully bio-based agents (Teacă et al. 2019). Tannins are an example of those wood-derived components. They are highmolecular weight polyphenols that naturally occur as secondary metabolites in plants and provide chemical defense (Haslam 1989; Hagermann 2002).

The potential role of tannins in wood protection was earlier mentioned by Laks et al. (1988). Not only do they have natural origin and abundant availability, but they can even exceed the performance of chemical treatments, such as CCB (Da Silveira et al. 2017), whose application is becoming diminished due to its negative environmental impacts (Teacă et al. 2019). Other research groups have mainly emphasized the use of hardeners for tannins since their low reactivity hinders polymerization within wood and 
supports unwanted leaching (Thevenon et al. 2009; Navarrete et al. 2013; Sommerauer et al. 2019). With increasing restrictions on emissions, the tannin hardening process demands replacement of toxic formaldehyde (Pizzi 2019). Besides selecting other chemicals acting as functional hardeners, another option for tannins utilization is their hydrolysis, in which self-polymerization can be achieved through the separation into smaller, reactive fractions. Hydrolytical treatment can be performed in acid or alkaline environments; however, polyphenols show higher stability at acidic $\mathrm{pH}$. Therefore, strong acid of low concentration is beneficiary for polyphenol stability maintenance (Domínguez-Rodríguez et al. 2017). The acid induces cleavage of the interflavanyl bonds in condensed tannins in the formation of heterogeneous oligomeric- or even polymeric phenolic compounds, so-called phlobaphenes, which are hydrophobic (Foo and Karchesy 1989; Arbenz and Avérous 2015). The implementation of hydrophobizing agent into wood might improve its natural durability, as the hydrophilic character of wood polymers easily forms H-bridges with water; this milieu facilitates the growth of wood-destroying organisms.

The presence of strong acid has a damaging effect on wood polymers (Hill 2006); consequently, the acid has to be removed from the tannin solution before the wood impregnation. The successful elimination of mineral acid in combination with wood modification was previously reported by Zollfrank (2001), who immersed wood specimens in pyridine after silylation. Pyridine acted as a scavenger for releasing hydrochloric acid, ensuring that the specimens remained intact from the strong acidic environment. Thus, no destruction on cell walls was detected.

As an organic solvent, pyridine is difficult to reuse and dispose, thus favoring water as an environmentally friendly solvent. The simplest way would be to increase the drying temperature of acidified water solution above the boiling temperature, which would solve the issue but would also lead to unwanted and uncontrolled fast phlobaphene formation. To remove acid from the solution, freeze-drying (lyophilization) can be considered. Because the greatest benefit of hydrochloric acid is its volatile character, reduced pressure and low drying temperature (i.e., below zero degree Celsius) offer a suitable approach for temperature-sensible compounds.

After the freeze-drying, the bonded chlorine may remain in the extract, and it may have an additional function in wood preservation. Lotz (1993) confirmed the advantage of halogenated tannins with bromine for a higher decay and weathering resistance. For instance, halogenated flavonoids have been investigated to obtain multifunctional bioactive molecules for medicinal purpose (Bernini et al. 2015).

This work examined the mild acid hydrolysis of commercial wattle tannin. To ensure low chlorine content in the tannin structure, highly diluted hydrochloric acid was applied with an extended reaction time. Changes in leaching resistance of treated beech wood and the suitability of this procedure were investigated. For the first time, freezedrying after acid catalyzed hydrolysis was used for this purpose, i.e., in the development of tannin-based wood preservation system.

\section{EXPERIMENTAL}

\section{Original Tannin Extract and Beech Wood Specimens}

Industrial hot water tannin extract from the bark of black wattle (Acacia mearnsii) was kindly provided by TANAC S.A. (Montenegro, RS, Brazil). For the impregnation of beech wood (Fagus sylvatica L.) from the stands close to Brno (Czech Republic), 
specimens without visible defects, cracks or discolorations were cut into $25 \times 15 \times 5 \mathrm{~mm}$ $(\mathrm{L} \times \mathrm{R} \times \mathrm{T}$ direction).

\section{Hydrolytical Treatment of Tannin Powder}

The tannin fractionation followed hydrolytical reaction using hydrochloric acid. Proportionally, $1 \mathrm{~g}$ of tannin powder was dissolved in $5 \mathrm{~mL}$ of diluted $\mathrm{HCl}$ of concentration 1 and 10 mmol. $\mathrm{L}^{-1}$ (labeled as $\mathrm{B}$ and $\mathrm{C}$, respectively), and stirred for $2 \mathrm{~h}$ at ambient temperature $\left(25^{\circ} \mathrm{C}\right)$. The whole solution was kept in a freezer to stop the hydrolysis and to obtain the solid state necessary for the subsequent lyophilization. In this step, water with present volatile acid was separated from the modified tannin under vacuum and constant drying temperature of $-55{ }^{\circ} \mathrm{C}$ using LaboGene CoolSafe (Allerød, Denmark). The fullydried, modified powders were further applied as waterborne wood impregnation agents. The experimental set-up is illustrated in Fig. 1.

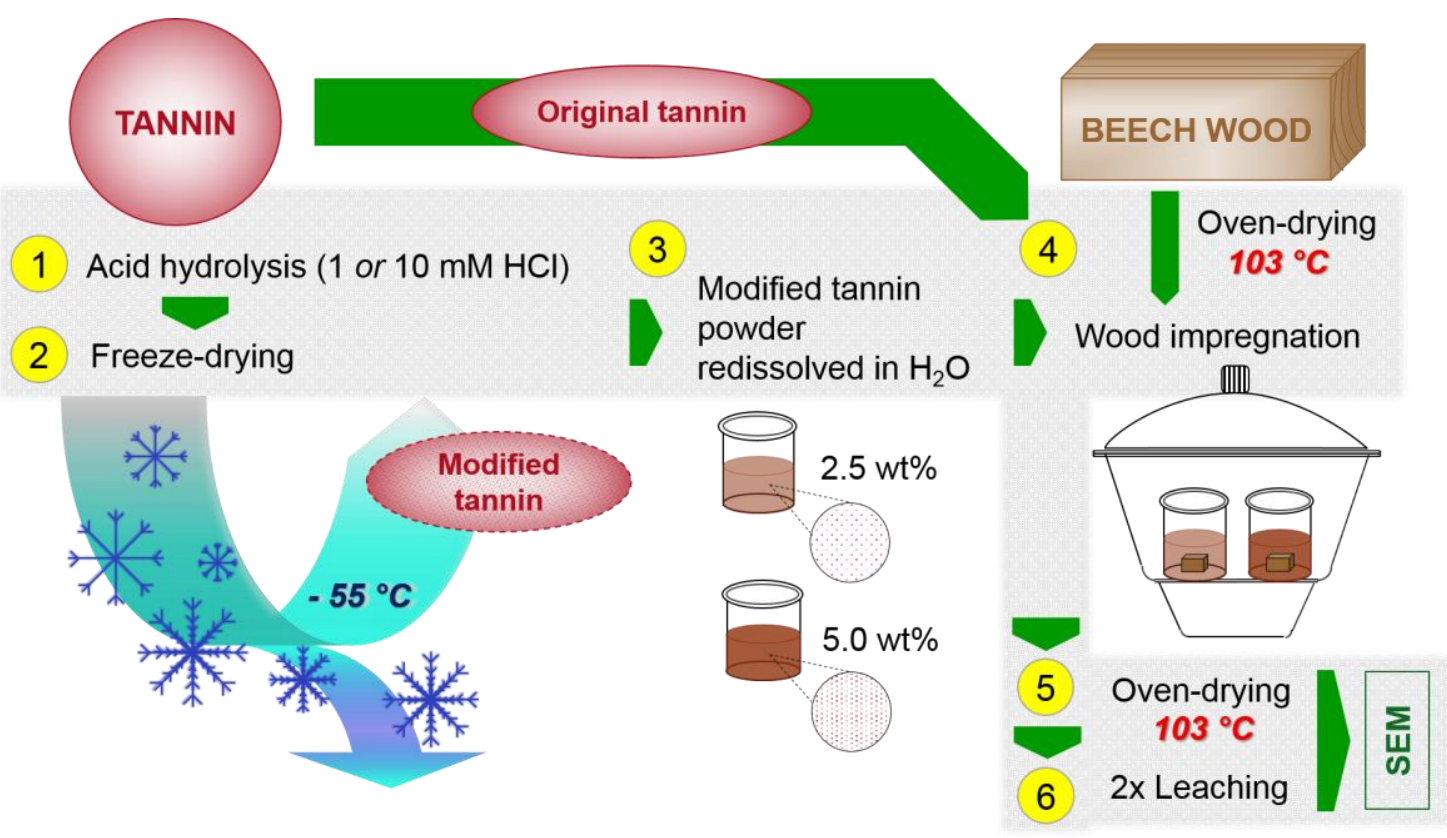

Fig. 1. Schematic representation of the experiment

\section{Wood Impregnation Parameters}

The original tannin powder (used as a reference A) and those after the hydrolysis procedure $(\mathrm{B}$ and $\mathrm{C}$ ) were dissolved in demineralized water to get the final concentration of $2.5 \mathrm{wt} \%$ (lower concentration: A1, B1, C1) and $5.0 \mathrm{wt} \%$ (higher concentration: A2, B2, $\mathrm{C} 2$ ). Five beech wood specimens for each type were oven-dried at $103 \pm 2{ }^{\circ} \mathrm{C}$ (for $12 \mathrm{~h}$ ), weighed, placed in a glass beaker, and immersed in an aqueous solution of desired tannin concentration fully covering the specimens' surface. The impregnation was performed at ambient temperature $\left(25^{\circ} \mathrm{C}\right)$, in a desiccator under vacuum allowing air evacuation, which allowed diffusion into wood cell structures. The air evacuation took 11 min and was followed by a further 20 min under already established vacuum. The system was carried to room pressure, and the wood specimens were kept in the solution for $6 \mathrm{~h}$. The solid uptake of tannin in treated specimens was calculated after oven-drying at $103 \pm$ $2{ }^{\circ} \mathrm{C}$ (for $12 \mathrm{~h}$ ) according to Eq. 1,

$$
W P G=[(\text { oven-dried impregnated }- \text { oven-dried }) / \text { oven-dried }] \times 100 \%
$$


where the resulting weight per cent gain $(W P G)$ is expressed as a solid uptake (\%), weight of a modified specimen as oven-dried impregnated $(\mathrm{g})$, and the weight prior to the impregnation as oven-dried $(\mathrm{g})$.

\section{Leaching Test}

To determine the effect of hydrolytical pre-treatment of the extract on the tannin leachability from impregnated beech, two leaching cycles were performed. After $24 \mathrm{~h}$ of immersion in demineralized water at ambient temperature, the specimens' oven-dried mass (drying at $103 \pm 2{ }^{\circ} \mathrm{C}$ ) was recorded. The conditions for the second leaching step were kept the same as for the first one.

The remaining solid of the agent after each leaching was expressed in $\%$, as shown in Eq. 2,

$$
W P G_{L i}=\left\{\left[(\text { leached })_{i}-\text { oven-dried }\right] / \text { oven-dried }\right\} \times 100 \%
$$

where $W P G_{L i}$ is solid tannin present in a specimen after $i$-leaching step; leached is weight of a leached specimen after $i$-leaching ( $\mathrm{g}$ ); oven-dried represents a specimen weight before impregnation (g); and index $i=\{1,2\}$ indicates the first and second leaching, respectively.

\section{Scanning Electron Microscopy (SEM)}

The surface morphology of the impregnated wood specimens was investigated with a scanning electron microscope (Hitachi S-3400N, Tokyo, Japan) with an accelerating voltage set at $10 \mathrm{kV}$. Wood specimens were slightly wetted by a water drop for cutting, and then the plane surface was scanned from the cross section at an atmosphere of $60 \mathrm{~Pa}$.

\section{Data Evaluation}

All data were processed with SPSS Statistics 19 (IBM, Armonk, NY, USA); the significance of differences was analyzed using the analysis of variance (ANOVA) and Tukey's post hoc test at a $95 \%$ confidence level.

\section{RESULTS AND DISCUSSION}

\section{Acid Treatment and Lyophilization of Tannin Extract}

To avoid possible harmful effects of present acid on wood polymers, the strong acid was eliminated from the solution through freeze-drying. Based on the dried state of the powdered extract just after the hydrolytical treatment and subsequent lyophilization, it was assumed that the selected drying procedure was effective. Moreover, the water solubility of the tannin extract was not affected by the hydrolysis and the extract could be re-dissolved again in water for the wood impregnation.

\section{Wood impregnation efficiency and tannin leaching resistance}

The results obtained from wood impregnation and the following leaching tests are presented in Table 1. The gravimetrical changes monitored through the wood modification process showed only small differences among selected groups (low tannin concentration: A1 vs. B1 vs. C1; higher tannin concentration A2 vs. B2 vs. C2). While the solid uptake (WPG) was expected to be higher due to the desired fractionation of the tannin (i.e., $\mathrm{B}, \mathrm{C}$ series), the concentration itself applied for the impregnation solution appeared as a more important factor. 
Table 1. Weight Gain after Beech Wood Impregnation with a Hydrolytically Modified Tannin Solution and after Two Subsequent Leaching Cycles

\begin{tabular}{|c|c|c|c|c|}
\hline Tannin type & $\begin{array}{c}\text { Tannin } \\
\text { concentration } \\
\text { in impregnation } \\
\text { solution } \\
(\text { wt\%) }\end{array}$ & $\begin{array}{c}\text { Weight per } \\
\text { cent gain after } \\
\text { impregnation - } \\
\text { WPG } \\
(\%)\end{array}$ & $\begin{array}{c}\text { WPGL1 } \\
\text { after first } \\
\text { leaching } \\
(\%)\end{array}$ & $\begin{array}{c}\text { WPGL2 } \\
\text { after second } \\
\text { leaching } \\
(\%)\end{array}$ \\
\hline Original tannin (A1) & 2.5 & $2.36 \pm 0.05^{\mathrm{a}, \mathrm{b}}$ & $1.02 \pm 0.09^{\mathrm{c}}$ & $0.74 \pm 0.12$ \\
\hline $\begin{array}{c}\text { Mildly hydrolyzed } \\
\text { (B1) }\end{array}$ & 2.5 & $2.17 \pm 0.11^{\mathrm{a}}$ & $0.81 \pm 0.14$ & $0.55 \pm 0.20$ \\
\hline Hydrolyzed (C1) & 2.5 & $2.02 \pm 0.13^{\mathrm{b}}$ & $0.74 \pm 0.18^{\mathrm{c}}$ & $0.54 \pm 0.21$ \\
\hline Original tannin (A2) & 5.0 & $4.75 \pm 0.17$ & $2.43 \pm 0.13^{\mathrm{d}}$ & $1.98 \pm 0.14$ \\
\hline $\begin{array}{c}\text { Mildly hydrolyzed } \\
\text { (B2) }\end{array}$ & 5.0 & $4.89 \pm 0.07$ & $2.24 \pm 0.12^{\mathrm{d}}$ & $1.86 \pm 0.06$ \\
\hline Hydrolyzed (C2) & 5.0 & $4.89 \pm 0.11$ & $2.27 \pm 0.07$ & $1.94 \pm 0.04$ \\
\hline Signicant difer
\end{tabular}

a,b,c,d Significant difference between the groups at the level $\alpha=0.05$ is represented with the same index label

* While the percentual expression for tannin concentration is based on the weight of solid in the weight of the impregnation solution (wt\%), other columns are calculated compared to wood specimens' weight

High leaching might be associated with the ability of tannins to reversibly bond with saccharides (Haslam 1989), in particular hemicelluloses (Bariska and Pizzi 1986) that are spatially accessible, and after exposure to water, the whole structure becomes partially soluble. This outcome is in accordance with research by Jakobek (2015). The bad performance of pre-treated tannin specimens is explained by Venter et al. (2012): some of the interflavanyl bonds present in wattle bark tannins cannot be hydrolyzed with acid due to steric hindrance because the extract tends to keep its oligomeric form. As Hill (2006) suggested, additional physically based interaction of wood polymers, such as hydrogen bond formation, is beneficial for a better penetration of the impregnation agent. Better stability is expected when the agent interacts with the cell wall. However, impregnation with lumen filling creates unstable bridges that fail over time. Those failures appearing as lower levels of leaching resistance were detected while lowering the water content in beech specimens at a higher temperature. Thus, wood drying temperature set at $100{ }^{\circ} \mathrm{C}$, which has been commonly applied in the modification to obtain zero moisture content, has a destructive effect on the structure, i.e. typically visible as cracks among rays (Fig. 2a). Structural damage might also affect the leaching resistance of beech impregnated with tannins. Tannins that are fully water-soluble are taken away during water evaporation with water molecules faster than tannin new bond sites occur.

These findings correspond with observations via scanning electron microscopy (Fig. 2). The distribution of the impregnation agent was homogenous (Fig. 2a), reaching not all anatomical elements due to the relatively low concentration of the solid agent used in this study. Due to a higher solid uptake in the case of higher tannin concentration used for the impregnation, an increased number of filled vessels was expected. The extraneously added tannin primarily filled the vessel lumens (Fig. 2c), which confirms the investigation without any tannin hydrolysis done by Tondi et al. (2013). A limited amount of tannin was also present in lumens and/or cell walls of other anatomical elements. Vek et al. (2020) observed similar deposition in beech. Their impregnation involved hydrophilic heartwood extract of black locust that contained the same main unit - robinetin - as the wattle bark extract (Venter et al. 2012); this accumulated in a crystalline form on the lumina surfaces. 
While some of the vessels were filled after the wood treatment (Fig. 2a, 2c), the impregnation agent disappeared from all vessels after the leaching (Fig. 2b, 2d), but smaller tannin parts remained blocked in the fibers. Their presence was confirmed by the positive percentage of WPG after the leaching cycles. Due to temperature and moisture fluctuation happening in outdoor conditions, the behavior of treated beech wood exposed to real conditions would need to be evaluated first. It is questionable, however, whether the final tannin solid uptake would remain at a constant level or decrease over time toward zero.
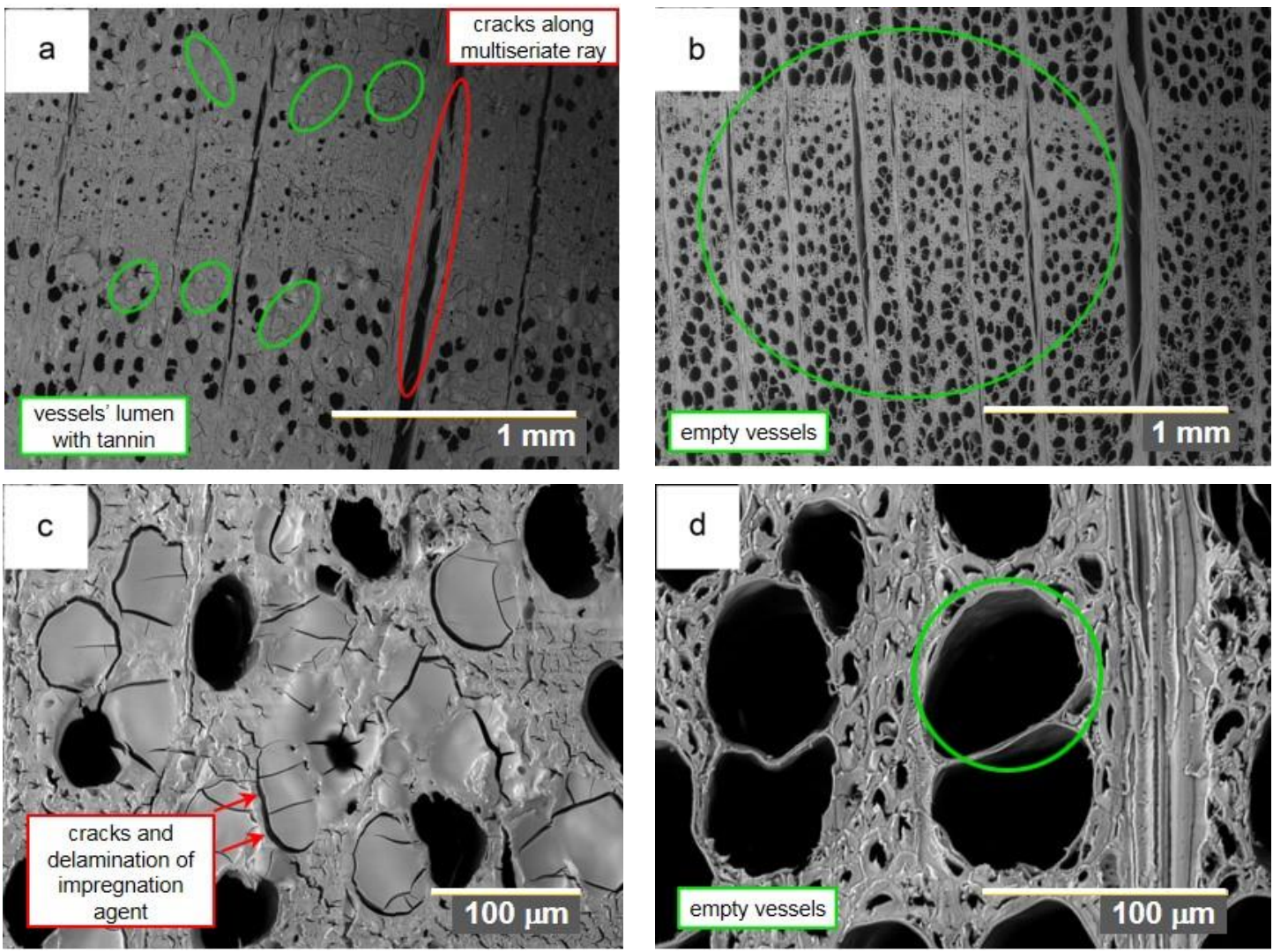

Fig. 2. SEM images of beech wood cross section after impregnation with $5.0 \mathrm{wt} \%$ of original tannin (A2) (a, c) and after two leaching cycles (b, d)
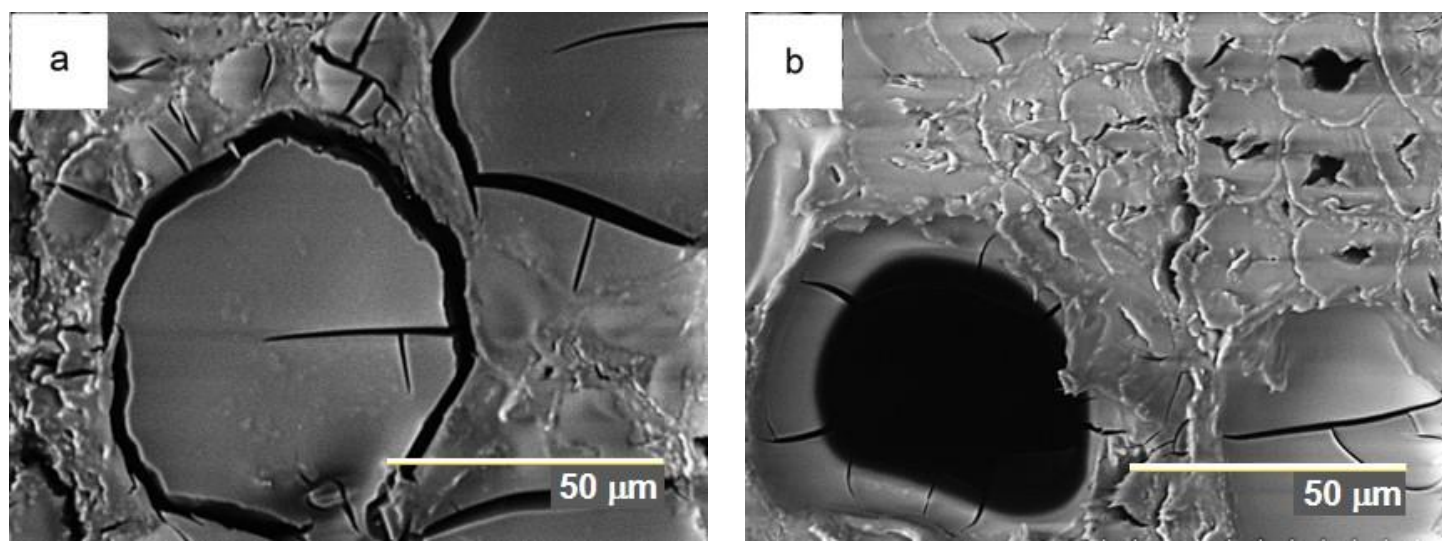

Fig. 3. SEM images of beech wood cross section after impregnation with either crude tannin (A2) (a) or hydrolytically treated tannin (C2) (b), magnification $1000 \times$ 
The expected higher leaching resistance of the modified tannin was not explicitly detected after the acid treatment. Moreover, the original tannin showed delamination from vessels and no obvious connection to their cell walls (Fig. 3a). As illustrated below, hydrolytically treated tannins, due to a changed chemical functionality, had a slightly better affinity to lumens of vessels (Fig. 3b).

However, the desired hydrophobic properties of created phlobaphenes are of a lower impact if they predominantly remain in the water-conductive paths of wood without formation of stronger bonding sites. The worse efficacy of the impregnation agent could be influenced by too mild tannin pre-treatment that did not lead to sufficient tannin fractionation. Thus, due to dimensional hindrance, only a small part of the extract could access and block fibers. Deeper understanding of hydrolytical reaction settings and final physico-chemical properties of the modified tannin extract have become the subject of following study.

In sum, tannin extracts from sustainable resources are gaining attention in various fields, from nutritional and medicinal benefits up to technologically related questions. Therefore, the knowledge expansion by the so-called "trial-and-error approach" (e.g., case studies) is needed for further material developments of biodegradable origin.

\section{CONCLUSIONS}

1. Freeze-drying of tannin extract was completed until dryness due to lowered temperature and pressure; thus, a sensitive removal of volatile acid without affecting the tannin solubility was achieved.

2. The selected conditions for the hydrolytical reaction of tannins did not lead to sufficient leaching resistance of tannins in beech wood. This result implies that the reaction with diluted acid did not change the molecular dimensions of tannins to the expected extent and hindered them from a deeper penetration into wood cell walls as well as from their better distribution.

3. More than $25 \%$ of the impregnation agent remaining after two leaching steps (applicable for all tested cases). This confirmed tannin's partial fixation via filling wood fibers, and thus, the positive effect of the treatment. However, the resulting distinctions between treatments efficacy was not observable.

\section{ACKNOWLEDGMENTS}

The authors acknowledge the support of the Internal Grant Agency of the FFWT MENDELU, Grant No. LDF_VP_2019035; and the European regional development fund from the Interreg Austria-Czech Republic program, project VALID "Added Value from Residuals". A special thanks goes to Radim Rousek for the preparation of wood specimens. 


\section{REFERENCES CITED}

Arbenz, A., and Avérous, L. (2015). "Chemical modification of tannins to elaborate aromatic biobased macromolecular architectures," Green Chemistry 17(5), 26262646. DOI: 10.1039/C5GC00282F

Bariska, M., and Pizzi, A. (1986). "The interaction of polyflavonoid tannins with wood cell-walls," Holzforschung 40(5), 299-302. DOI: 10.1515/hfsg.1986.40.5.299

Bernini, R., Pasqualetti, M., Provenzano, G., and Tempesta, S. (2015). "Ecofriendly synthesis of halogenated flavonoids and evaluation of their antifungal activity," New Journal of Chemistry 39, 2980-2987. DOI: 10.1039/C5NJ00258C

Borges, C. C., Tonoli, G. H. D., Cruz, T. M., Duarte, P. J., and Junqueira, T. A. (2018). "Nanoparticles-based wood preservatives: The next generation of wood protection?," Cerne 24(4), 397-407. DOI: 10.1590/01047760201824042531

Da Silveira, A. G., Santini, E. J., Kulczynski, S. M., Trevisan, R., Wastowski, A. D., and Gatto, D. A. (2017). "Tannic extract potential as natural wood preservative of Acacia mearnsii," Annals of the Brazilian Academy of Sciences 89(4), 3031-3038. DOI: 10.1590/0001-3765201720170485

Domínguez-Rodríguez, G., Marina, M. L., and Plaza, M. (2017). "Strategies for the extraction and analysis of non-extractable polyphenols from plants," Journal of Chromatography A 1514, 1-15. DOI: 10.1016/j.chroma.2017.07.066

Foo, L. Y., and Karchesy, J. J. (1989). "Chemical nature of phlobaphenes," in: Chemistry and Significance of Condensed Tannins, R. W. Hemingway and J. J. Karchesy (eds.), Plenum Press, New York, pp. 109-118. DOI: 10.1007/978-1-4684-7511-1_6

Hagermann, A. E. (2002). Tannin Handbook, Miami University, Oxford OH 45056.

Haslam, E. (1989). Plant Polyphenols: Vegetable Tannins Revisited, Cambridge University Press, Cambridge.

Hill, C. A. S. (2006). Wood Modification: Chemical, Thermal and Other Processes, John Wiley \& Sons, Hoboken, NJ, USA. DOI: 10.1002/0470021748

Jakobek, L. (2015). "Interactions of polyphenols with carbohydrates, lipids and proteins," Food Chemistry 175, 556-567. DOI: 10.1016/j.foodchem.2014.12.013

Laks, P. E., Mckaig, P. A., and Hemingway, R. W. (1988). "Flavonoid biocides: Wood preservatives based on condensed tannins," Holzforschung 42(5), 299-306. DOI: 10.1515/hfsg.1988.42.5.299

Lotz, W. R. (1993). "Wood preservation systems including halogenated tannin extracts," U. S. Patent No. 5270083A.

Navarrete, P., Pizzi, A., Bertaud, F., and Rigolet, S. (2013). "Condensed tannin reactivity inhibition by internal rearrangements: Detection by CP-MAS 13C NMR," Maderas. Ciencia y tecnología 13(1), 59-68. DOI: 10.4067/S0718-221X2011000100006

Pizzi, A. (2019). "Tannins: Prospectives and actual industrial applications," Biomolecules 9(8), 344. DOI: 10.3390/biom9080344

Reinprecht, L. (2016). Wood Deterioration, Protection and Maintenance, Wiley \& Sons, Oxford, UK. DOI: 10.1002/9781119106500

Sommerauer, L., Thevenon, M.-F., Petutschnigg, A., and Tondi, G. (2019). "Effect of hardening parameters of wood preservatives based on tannin copolymers," Holzforschung 73(5), 457-467. DOI: 10.1515/hf-2018-0130

Teacă, C.-A., Roşu, D., Mustaţă, F., Rusu, T., Roşu, L., Roşca, I., and Varganici, C.-D. (2019). "Natural bio-based products for wood coating and protection against degradation: A review," BioResources 14(2), 4873-4901. DOI: 


\subsection{6/biores.14.2.Teaca}

Teng, T.-J., Arip, M. N. M., Sudesh, K., Nemoikina, A., Jalaludin, Z., Ng, E.-P., and Lee, H.-L. (2018). "Conventional technology and nanotechnology in wood preservation: A review," BioResources 13(4), 9220-9252. DOI: 10.15376/biores.13.4.Teng

Thevenon, M.-F., Tondi, G., and Pizzi, A. (2009). "High performance tannin resin-boron wood preservatives for outdoor end-uses," European Journal of Wood and Wood Products 67(1), 89-93. DOI: 10.1007/s00107-008-0290-0

Tondi, G., Thevenon, M. F., Mies, B., Standfest, G., Petutschnigg, A., and Wieland, S. (2013). "Impregnation of Scots pine and beech with tannin solutions: Effect of viscosity and wood anatomy in wood infiltration," Wood Science and Technology 47(3), 615-626. DOI: 10.1007/s00226-012-0524-5

Vek, V., Balzano, A., Poljanšek, I., Humar, M., Oven, P. (2020). "Improving fungal decay resistance of less durable sapwood by impregnation with scots pine knotwood and black locust heartwood hydrophilic extractives with antifungal or antioxidant properties," Forests 11, 1024. DOI: 10.3390/F11091024

Venter, P. B., Senekal, N. D., Kemp, G., Amra-Jordaan, M., Khan, P., Bonnet, S. L., and van der Westhuizen, J. H. (2012). "Analysis of commercial proanthocyanidins. Part 3: The chemical composition of wattle (Acacia mearnsii) bark extract," Phytochemistry 83, 153-167. DOI: 10.1016/j.phytochem.2012.07.012

Zollfrank, C. (2001). "Silylation of solid beech wood," Wood Science and Technology 35, 183-189. DOI: $10.1007 / \mathrm{s} 002260000071$

Article submitted: November 13, 2020; Peer review completed: January 2, 2021; Revised version received and accepted: February 11, 2021; Published: February 17, 2021.

DOI: $10.15376 /$ biores.16.2.2548-2556 